\title{
Application of the Beers Criteria to Alternate Level of Care Patients in Hospital Inpatient Units
}

\author{
Heather Slaney, Stacey MacAulay, Janice Irvine-Meek, and Joshua Murray
}

\begin{abstract}
Background: The Beers criteria were developed to help in identifying potentially inappropriate medications (PIMs) for elderly patients. These medications are often associated with adverse events and limited effectiveness in older adults. Patients awaiting an alternate level of care (ALC patients) are those who no longer require acute care hospital services and are waiting for placement elsewhere. They are often elderly, have complex medication regimens, and are at high risk of adverse events. At the time of this study no studies had applied the Beers criteria to ALC patients in Canadian hospitals.
\end{abstract}

Objectives: To determine the proportion of ALC patients receiving PIMs and the proportion experiencing selected PIM-related adverse events.

Methods: A retrospective chart review of ALC patients 65 years of age or older was performed to identify PIMs and the occurrence of selected adverse events (specifically central nervous system [CNS] events, falls, bradycardia, hypoglycemia, seizures, insomnia, gastrointestinal bleeding, and urinary tract infections). A logistic regression model with a random intercept for each patient was constructed to estimate odds ratios and probabilities of adverse events.

Results: Fifty-two ALC patients were included in the study. Of these, 48 (92\%) were taking a PIM. Of the 922 adverse events evaluated, 407 (44.1\%) were associated with a regularly scheduled PIM. Among patients who were taking regularly scheduled PIMs, there was a significantly increased probability of an adverse CNS event and of a fall ( $p<0.001$ for both). The most common PIM medication classes were first-generation antihistamines (24 [ $46 \%$ ] of the 52 patients), antipsychotics (21 patients [40\%]), short-acting benzodiazepines (15 patients [29\%]), and nonbenzodiazepine hypnotics (14 patients [27\%]).

Conclusions: A high proportion of ALC patients were taking PIMs and experienced an adverse event that may have been related to these drugs. These findings suggest that the ALC population might benefit from regular medication review and monitoring to prevent or detect adverse events.

Keywords: Beers criteria, alternate level of care, retrospective, adverse events, Canad

\section{RÉSUMÉ}

Contexte : Les critères de Beers ont été élaborés afin d'aider à détecter l'utilisation de médicaments potentiellement inappropriés (MPI) auprès des patients âgés. L'on associe souvent les MPI à des événements indésirables, et leur efficacité chez les personnes âgées est limitée. Les patients en attente d'un autre niveau de soins (patients ANS) sont ceux qui ne nécessitent plus de soins de courte durée de l'hôpital et qui attendent d'être déplacés vers un autre établissement. Il s'agit souvent de personnes âgées ayant une panoplie complexe de traitements médicamenteux et présentant un risque élevé de subir des événements indésirables. Au moment de la présente recherche, aucune étude n’avait appliqué les critères de Beers aux patients ANS des hôpitaux canadiens.

Objectifs : Déterminer quelles sont les proportions de patients ANS qui reçoivent des MPI et qui subissent certains événements indésirables choisis liés à ces médicaments.

Méthodes : Une analyse rétrospective des dossiers médicaux de patients ANS âgés de 65 ans et plus a été réalisée dans le but de relever les MPI ainsi que les cas de certains événements indésirables choisis (particulièrement les événements liés au système nerveux central, les chutes, la bradycardie, l'hypoglycémie, les convulsions, l'insomnie, les hémorragies gastro-intestinales et les infections urinaires). On a mis au point un modèle de régression logistique avec ordonnée à l'origine aléatoire pour chaque patient afin d'estimer les risques relatifs approchés ainsi que les probabilités d'événements indésirables.

Résultats : Au total, 52 patients ANS ont été admis à l'étude. De ceuxci, 48 (92\%) prenaient un MPI. Des 922 événements indésirables analysés, 407 (44,1\%) ont été associés à un MPI administré régulièrement. Parmi les patients prenant des MPI à une fréquence régulière, la probabilité de subir une chute ou un événement indésirable lié au système nerveux central était grandement accrue ( $p<0,001$ pour chacun). Les MPI les plus fréquents étaient : les antihistaminiques de première génération (24 [46\%] des 52 patients), les antipsychotiques (21 patients [40\%]), les benzodiazépines à action brève (15 patients [29\%]) et les hypnotiques non-benzodiazépines (14 patients [27\%]).

Conclusions : Un grand nombre de patients ANS prenaient des MPI et avaient subi un événement indésirable qui pouvait avoir été en lien avec ces médicaments. Ces résultats laissent croire que les patients ANS pourraient tirer avantage d'évaluations fréquentes de la pharmacothérapie et de surveillance afin de prévenir les événements indésirables ou de les détecter.

Mots clés : critères de Beers, autre niveau de soins, analyse rétrospective, événements indésirables, Canada 


\section{INTRODUCTION}

A $\mathrm{n}$ increasing proportion of beds within Canadian hospitals are being occupied by patients awaiting an alternate level of care (ALC patients), i.e., patients who no longer require acute medical services and are typically awaiting placement in a long-term care facility. ${ }^{1}$ According to the Canadian Institute for Health Information, ALC patients accounted for $5 \%$ of hospital admissions and $14 \%$ of hospital days in acute care facilities in $2007 / 2008$, such that on any given day such patients occupied almost 5200 beds. $^{1}$ ALC patients often have complex medication regimens and are usually elderly, with lengths of stay that can vary from a few days to several months. ${ }^{1,2}$ A recent Canadian study of ALC patients further identified that the clinical characteristics significantly associated with greater ALC lengths of stay were morbid obesity, psychiatric diagnosis, abusive behaviours, and stroke. ${ }^{3}$

The project described here was carried out in a 380-bed acute care hospital site located within a large health region in Atlantic Canada. A 2012 chart review of ALC patients in all facilities within the health region showed that the overall mean length of stay before discharge to a nursing home was 262.8 days. $^{4}$

The Decision Support team at the study site reported that, between June 1, 2011, and June 1, 2012, a total of 229 patients designated ALC were discharged after an average length of stay of 125 days, with an average of 98 days with ALC status. Of that group, $189(82.5 \%)$ were older than 65 years of age at the time of discharge. Patients at the study site usually receive direct patient care from the hospital's pharmacy team on admission. However, once patients are designated as ALC, they receive care from a pharmacist only if an acute issue is identified by the health care team, although the health region's Health and Aging Network Standards recommend that each ALC patient receive a medication review by the interdisciplinary team every 1 to 2 months. ${ }^{5}$

In 2012, the American Geriatrics Society updated the Beers criteria, ${ }^{6}$ a tool originally developed to help in identifying potentially inappropriate medications (PIMs) for elderly patients. The update involved a rigorous, evidence-based systematic review. The goal of the Beers criteria is to improve the care of older adults ( $\geq 65$ years) by reducing their exposure to PIMs. ${ }^{6}$ PIMs defined by the Beers criteria have been associated with adverse events and limited effectiveness in older adults. ${ }^{7-11}$ Without appropriate monitoring, a patient for whom a PIM (as defined by the Beers criteria) is prescribed could be at risk of poor outcomes, regardless of the appropriateness of that drug for the particular individual..$^{8,10}$

As a set of "explicit criteria", the Beers criteria can be readily applied to large samples of people and can therefore be used as a valuable quality measure. ${ }^{12}$ The current study used the Beers criteria as a framework to determine the proportion of hospitalized ALC patients who may be at risk of medication-related problems and may therefore benefit from more frequent pharmacist follow-up. A literature search (conducted in September 2012 and updated in April 2014) did not yield any studies in which the Beers criteria framework was applied to ALC patients in Canadian hospitals; therefore, this study represents a substantial opportunity to add to the existing literature. More specifically, this study will help to determine whether ALC patients at the study facility have unmet medication-related needs and whether they might benefit from routine medication reviews and monitoring by a pharmacist or physician.

The primary objectives of this study were to determine the proportion of ALC patients at the study site who were receiving one or more Beers criteria PIMs and the proportion who experienced adverse events possibly attributable to those medications. Secondary objectives were to identify the PIMs most commonly prescribed in the ALC patient population and any related adverse effects.

\section{METHODS}

This retrospective cohort study was conducted at an acute care community hospital that is part of a large health care organization. A Project Advisory Team was established, consisting of a geriatrician, a nurse manager for an ALC unit, and 2 clinical pharmacists (one of whom [J.I.-M.] specialized in geriatrics). Methodologic and statistical analysis support was provided by the institution's Applied Health Research Coordinator. The study protocol was approved by the Horizon Health Network Research Ethics Board on October 31, 2012. Informed consent was not required for this retrospective chart review.

\section{Participants}

The following inclusion criteria were applied. All patients who were designated as ALC at the study site as of September 1, 2012, were identified with the assistance of the Decision Support team. Patients were included in the study if they were 65 years of age or older at the time of designation as an ALC patient.

The following exclusion criteria were applied. Patients with ALC status for less than 30 days or longer than 365 days as of September 1, 2012, were excluded. Also excluded were ALC patients who were designated to receive palliative care for more than 5 days, as the Beers criteria are not applicable in palliative care settings. ${ }^{6}$ Patients receiving personal and financial guardianship services from the office of the Public Trustee ${ }^{13}$ were also excluded, as they often experience complicated social situations that may significantly affect the length of stay.

\section{Data Collection}

The primary researcher (H.S.) collected information from patients' paper and electronic charts using a standardized data collection sheet prepared for this study. Baseline information collected for each patient were age, sex, admission date, ALC 
date, discharge date, height, weight, and serum creatinine level. Each patient's medication record was scanned for any of the potentially inappropriate medications and classes listed in Table 2 of the 2012 Beers criteria update, ${ }^{6}$ and these were recorded. Drugs listed in the Beers criteria table but not available in Canada (as per Health Canada's Drug Product Database on September 24, 2012) were removed from the data collection sheet (see Appendix 1 for the list of drugs removed). Information on zopiclone was collected in the place of eszopiclone. Prespecified areas of the patient's paper and electronic charts were then scanned for diseases and syndromes that can be exacerbated by the Beers criteria PIMS (because of drug-disease or drugsyndrome interactions), as listed in Table 3 of the 2012 Beers criteria update, ${ }^{6}$ and these were were also recorded. For the purposes of this study, the targeted adverse events were central nervous system (CNS) events, falls, bradycardia, hypoglycemia, seizures, insomnia, gastrointestinal bleeding, and urinary tract infections.

Information on patients' medications was collected at 3 time points. Time point 1 (T1) was defined as 1 month after the first date the patient was designated as an ALC patient. Time point 3 (T3) was the date of discharge from hospital, the date of death, or December 31, 2012 (if the patient was still in hospital as of that date). Time point 2 (T2) was defined as midway between $\mathrm{T} 1$ and $\mathrm{T} 3$.

For each PIM identified at T1, T2, and T3, the class and name of the medication, start and stop dates, and whether the drug was ordered for regular or as-needed (PRN) administration were recorded. If the patient was continued on the medication beyond the study period, T3 was used as the stop date. Provided that use of a medication intersected with 1 of the 3 time points, it was counted once under the total number of PIMs for that patient, even if the dose was changed multiple times or the medication was stopped and restarted.

For each targeted adverse event that occurred on or between $\mathrm{T} 1$ and T3, the date was recorded. The medications were then reviewed to determine if the patient was taking a PIM on that specific date. If a regularly scheduled PIM was ordered for the patient at that time and the medication was one that could have been related to the adverse event, the association was recorded as "yes". If a regularly scheduled PIM was not prescribed for that patient or had been prescribed but was not known to cause the specific adverse event, the association was recorded as "no". Where a patient's diagnosis was unclear or an association between a regularly scheduled PIM and an adverse event was not straightforward, the researcher consulted the Project Advisory Team. Medication administration records were not reviewed to determine whether a PRN medication had been given before an adverse event. PRN medications were not included in the adverse event analysis.

To ensure accuracy and completeness of data collection and data entry into a Microsoft Excel (2003) database (Microsoft
Corporation, Redmond, Washington), information pertaining to $5(10 \%)$ of the patients included in the study was checked by another member of the research team (S.M.). For data security purposes, the primary researcher assigned a code to each patient. A code sheet was maintained for record-keeping and for use by the alternate investigator for checking data as described above.

\section{Data Sources and Definitions}

The patient's paper chart and electronic medical record were used to identify and record age (as of T3), sex, relevant diseases (as previously described), serum creatinine, and creatinine clearance. The serum creatinine value collected was the value measured closest to September 1, 2012. Creatinine clearance was calculated by inputting the patient's height and weight into the multiple (simultaneous) creatinine clearance calculators available online at the Global RPh website (globalrph.com), with the result reported being the result from the most appropriate equation for that patient, as chosen by the software. The height and weight recorded were the values measured closest to September 1, 2012. For patients with no height recorded in the electronic medical record, a value of $160 \mathrm{~cm}$ was used to estimate creatinine clearance.

Adverse events were identified on the basis of prespecified keywords from specific areas of the chart. Headings in the patient's nursing notes and progress notes were used to identify CNS adverse events such as episodes of disorientation, delirium, behavioural and psychological symptoms of dementia, or confusion. When the notes did not use descriptive headings (i.e., "assess" or "assessment"), the first 2 lines of the note were read to determine the context. Nursing and progress notes were also used to identify falls. The vitals flow chart and the diabetes flow record were used to identify days on which the patient had bradycardia (heart rate $<60$ beats $/ \mathrm{min}$ ) and episodes of hypoglycemia (blood glucose $<4.0 \mathrm{mmol} / \mathrm{L}$ ), respectively. Similarly, nursing and progress notes were used to identify the occurrence of seizures and insomnia. If keywords related to insomnia ("insomnia", "sleep disturbance", or "patient requests meds") were identified, the note was read to determine the quality of sleep, and occurrence of insomnia was recorded if sleep quality was recorded as "poor". Progress notes were used to identify incidents of gastrointestinal bleeding. Microbiology results (i.e., positive result on urine culture) in conjunction with concurrent antibiotic treatment were used to identify urinary tract infection.

Sources for the patient's diagnoses were the chart face sheet, history and physical sheet, paper or electronic progress notes, and consult notes.

The patient's medication history, as documented in the electronic medical record for the entire admission, was used to identify PIMs. Start and stop dates (according to the electronic medical record) were used to determine whether a PIM intersected any of the 3 time points. 


\section{Role of Project Advisory Team}

The Project Advisory Team helped to clarify cases in which diagnoses were unclear or there were questions about the appropriateness of a medication for a specific clinical scenario.

\section{Statistical Analysis}

The data were analyzed by the health region's Applied Health Research Coordinator, using R statistical software (version 2.15.3, March 2013). Baseline descriptive statistics were calculated for all participants. Means and standard deviations are presented for continuous variables, whereas counts and proportions are presented for categorical variables.

The primary objectives were to determine the proportion of ALC patients receiving one or more PIMs, as defined by the Beers criteria, and the proportion experiencing selected adverse events that might have been attributable to those medications.

Given the correlated nature of the adverse event data (with multiple observations per patient), a logistic regression model,

\section{Table 1. Baseline Characteristics of 52 Patients}

\begin{tabular}{|c|c|c|}
\hline Variable & $\begin{array}{l}\text { No. }(\%) \\
\quad \text { or } \mathrm{Me}\end{array}$ & $\begin{array}{l}\text { f Patients } \\
\text { a } \pm \text { SD }\end{array}$ \\
\hline Categorical & & \\
\hline Sex & & \\
\hline Female & 22 & $(42)$ \\
\hline Male & 30 & $(58)$ \\
\hline Heart failure & & \\
\hline No & 38 & (73) \\
\hline Yes & 14 & $(27)$ \\
\hline Seizures & & \\
\hline No & 44 & $(85)$ \\
\hline Yes & 8 & $(15)$ \\
\hline History of fractures & & \\
\hline No & 30 & $(58)$ \\
\hline Yes & 22 & $(42)$ \\
\hline History of falls & & \\
\hline No & 21 & $(40)$ \\
\hline Yes & 31 & $(60)$ \\
\hline Parkinson disease & & \\
\hline No & 47 & (90) \\
\hline Yes & 5 & $(10)$ \\
\hline Chronic kidney disease & & \\
\hline No & 39 & $(75)$ \\
\hline Yes & 13 & $(25)$ \\
\hline$\overline{\text { Dementia or cognitive imp }}$ & & \\
\hline No & 17 & (33) \\
\hline Yes & 35 & $(67)$ \\
\hline Continuous & & \\
\hline Age (years) & $82.69 \pm 8.03$ & (67-99) \\
\hline Height (cm) & $166.9 \pm 10.3$ & (139-188) \\
\hline Weight (kg) & $72.4 \pm 17.1$ & $(43.5-120.5)$ \\
\hline Length of stay (days) & $156 \pm 94.2$ & $(38-390)$ \\
\hline Serum creatinine $(\mu \mathrm{mol} / \mathrm{L})$ & $99.1 \pm 49.9$ & $(46-294)$ \\
\hline
\end{tabular}

$\overline{\mathrm{SD}}=$ standard deviation. with a random intercept for each patient, was constructed. The model was used to estimate odds ratios and probabilities of an adverse event for those patients who were taking PIMs; these are reported as log-odds ("est.") and standard error (SE). The odds ratios and probabilities were adjusted for age and sex.

\section{RESULTS}

A total of 52 ALC patients were included in the study, and their baseline characteristics are reported in Table 1. The proportion of patients receiving one or more PIMs (regular or PRN administration) was $92 \%$ (48/52), with 65\% (34/52) taking a regularly scheduled PIM. The mean number of classes of Beers criteria medications (regular or PRN) was 2.3 per patient (standard deviation [SD] 1.53), and the mean number of individual PIMs was 2.6 per patient (SD 1.72). The most common medication class was first-generation antihistamines (46\% [24/52]). Dimenhydrinate PRN was responsible for 92\% (22/24) of these. Antipsychotics were used for $40 \%$ (21/52) of the patients, short-acting benzodiazepines for 29\% (15/52), and nonbenzodiazepine hypnotics for $27 \%$ (14/52) (Table 2).

A total of 922 adverse events were recorded. Of these, 407 (44.1\%) were associated with a regularly scheduled PIM. Seventy-two percent $(36 / 50)$ of the falls were associated with a PIM, whereas 66.6\% (339/509) of CNS events, 13.2\% (29/220) of bradycardia events, and $14 \%$ (3/21) of urinary tract infections were associated with these drugs. None of the other targeted adverse events $(n=122)$, including insomnia and hypoglycemia, were associated with regularly scheduled PIMs. After adjustment for age and sex, a regularly scheduled PIM was associated with a $27 \%$ increase in the probability of experiencing a CNS event relative to another type of adverse event (est. $=3.41$, SE 0.29 , $p<0.001)$. Similarly, after adjustment for the same factors, a regularly scheduled PIM was associated with an $8 \%$ increase in the probability of a fall (est. $=3.26$, SE $0.55, p<0.001$ ).

The median number of adverse events experienced over the course of the study was 8 (interquartile range 2.75-20.5). Length of stay as an ALC patient was significantly associated with the number of adverse events experienced (Figure 1). For every additional week spent with ALC designation, a patient could expect 1.31 additional adverse events (SE 0.238, $t=5.5, p<0.001$ ).

Fifteen cases were referred to the Project Advisory Team for review. Cases brought to the panel were those in which the type and severity of dementia required clarification or where the primary researcher required an expert recommendation concerning either (1) the relationship between an adverse event and a medication or (2) the appropriateness of a medication for a particular patient.

\section{DISCUSSION}

To the authors' knowledge, this is the first study to apply the updated Beers criteria ${ }^{6}$ to ALC patients in Canada. The high 
This single copy is for your personal, non-commercial use only.

For permission to reprint multiple copies or to order presentation-ready copies for distribution, contact CJHP at cjhpedit@cshp.ca

Table 2. Most Prevalent Potentially Inappropriate Medications and Classes

\begin{tabular}{|c|c|c|c|c|}
\hline \multirow{3}{*}{$\begin{array}{l}\text { Class (No. and \% of Patients) } \\
\text { First-generation antihistamine: } \\
\text { dimenhydrinate }(n=22,42 \%)\end{array}$} & \multirow{3}{*}{$\begin{array}{l}\text { Medication } \\
\text { Dimenhydrinate }\end{array}$} & \multicolumn{3}{|c|}{ Dosage; No. (\%) of Patients } \\
\hline & & Regular & \multicolumn{2}{|c|}{ PRN } \\
\hline & & - & 22 & $(42)$ \\
\hline \multirow[t]{4}{*}{ Antipsychotics $(n=21,40 \%)$} & Olanzapine & $9(17)$ & 10 & (19) \\
\hline & Risperidone & $6 \quad(12)$ & 3 & (6) \\
\hline & Quetiapine & $5 \quad(10)$ & 3 & (6) \\
\hline & Haloperidol & - & 3 & (6) \\
\hline \multirow[t]{2}{*}{$\begin{array}{l}\text { Short-acting benzodiazepines } \\
(n=15,29 \%)\end{array}$} & $\begin{array}{l}\text { Lorazepam } \\
\text { Midazolam }\end{array}$ & $\begin{array}{ll}5 & (10) \\
- & \end{array}$ & $\begin{array}{r}11 \\
2\end{array}$ & $\begin{array}{r}(21) \\
(4)\end{array}$ \\
\hline & Oxazepam & - & 1 & $(2)$ \\
\hline $\begin{array}{l}\text { Nonbenzodiazepine } \\
\text { hypnotics }(n=14,27 \%)\end{array}$ & Zopiclone & (8) & 10 & (19) \\
\hline Gastrointestinal $(n=7,13 \%)$ & Metoclopramide & (4) & 5 & $(10)$ \\
\hline $\begin{array}{l}\text { Inhaled anticholinergic agents } \\
(n=7,13 \%)\end{array}$ & $\begin{array}{l}\text { Tiotropium } \\
\text { Ipratropium }\end{array}$ & $\begin{array}{ll}4 & (8) \\
3 & (6) \\
\end{array}$ & $\begin{array}{l}- \\
-\end{array}$ & \\
\hline Anticonvulsants $(n=6,12 \%)$ & $\begin{array}{l}\text { Gabapentin } \\
\text { Carbamazepine } \\
\text { Levetiracetam }\end{array}$ & $\begin{array}{rr}5 & (10) \\
1 & (2) \\
1 & (2)\end{array}$ & $\begin{array}{l}- \\
- \\
-\end{array}$ & \\
\hline $\begin{array}{l}\text { Long-acting benzodiazepines } \\
(\mathrm{n}=5,10 \%)\end{array}$ & $\begin{array}{l}\text { Clonazepam } \\
\text { Diazepam }\end{array}$ & $\begin{array}{rr}5 & (10) \\
1 & (2) \\
\end{array}$ & $\begin{array}{l}2 \\
-\end{array}$ & (4) \\
\hline $\begin{array}{l}\text { Other first-generation antihistamines } \\
(n=4,8 \%)\end{array}$ & $\begin{array}{l}\text { Hydroxyzine } \\
\text { Diphenhydramine } \\
\text { Hyoscine }\end{array}$ & $\begin{array}{ll}2 & (4) \\
- & \\
& -\end{array}$ & $\begin{array}{l}1 \\
1 \\
1\end{array}$ & $\begin{array}{l}\text { (2) } \\
(2) \\
(2)\end{array}$ \\
\hline Anti-infectives $(n=3,6 \%)$ & Nitrofurantoin & (6) & - & \\
\hline $\begin{array}{l}\text { Non-COX selective NSAIDs } \\
(n=3,6 \%)\end{array}$ & Ibuprofen & (6) & - & \\
\hline \multirow[t]{2}{*}{ Tertiary TCAs $(n=2,4 \%)$} & Doxepin & $(2)$ & - & \\
\hline & Amitriptyline & (2) & - & \\
\hline Antithrombotics $(n=2,4 \%)$ & Dabigatran & (4) & - & \\
\hline Antispasmodics $(n=1,2 \%)$ & Scopolamine & (2) & - & \\
\hline $\begin{array}{l}\text { Nondihydropyridine CCBs } \\
(n=1,2 \%)\end{array}$ & Diltiazem & (2) & - & \\
\hline \multirow[t]{3}{*}{ SSRI/SNRIS $(n=7,13 \%)$} & Citalopram & $5 \quad(10)$ & - & \\
\hline & Sertraline & $1 \quad(2)$ & - & \\
\hline & Venlafaxine & (2) & - & \\
\hline \multirow[t]{3}{*}{ Other $(n=3,6 \%)$} & Tramadol & (2) & - & \\
\hline & Bupropion & (2) & - & \\
\hline & $\begin{array}{l}\text { ASA for primary } \\
\text { prevention of CVD }\end{array}$ & $(2)$ & - & \\
\hline
\end{tabular}

percentage of ALC patients at the study site who received one or more PIMs and experienced associated adverse events is of concern. This small uncontrolled study serves to raise awareness about an important health policy issue pertaining to wait times for placement in nursing homes or special care homes.

The main limitation of using "explicit criteria" (such as the Beers criteria) as a quality measure is that they may not always consider the characteristics and needs of each individual patient. ${ }^{6,14}$ It is well established that the Beers criteria are not meant to replace clinical judgment. ${ }^{6,12}$ However these patients may still be at risk of experiencing adverse events and should be flagged for close monitoring. ${ }^{12}$ Over $90 \%$ of ALC patients in this study were taking either a regularly scheduled or a PRN PIM, and $65 \%$ had a regularly scheduled PIM. Other published studies have reported a high frequency of PIM use in elderly populations, with estimates ranging from about $20 \%$ to about $80 \% .^{15-19}$ The ALC population may benefit from more frequent medication reviews and monitoring to prevent or detect adverse events early, particularly in relation to the most common medication classes identified.

A high number of CNS events was recorded. Patients with dementia or cognitive impairment made up $67 \%$ of the study population, and many of these events may reflect behavioural and psychological symptoms of dementia. Although this analysis showed an increased probability of experiencing a PIM-induced CNS event, a confounding factor could have been that patients 


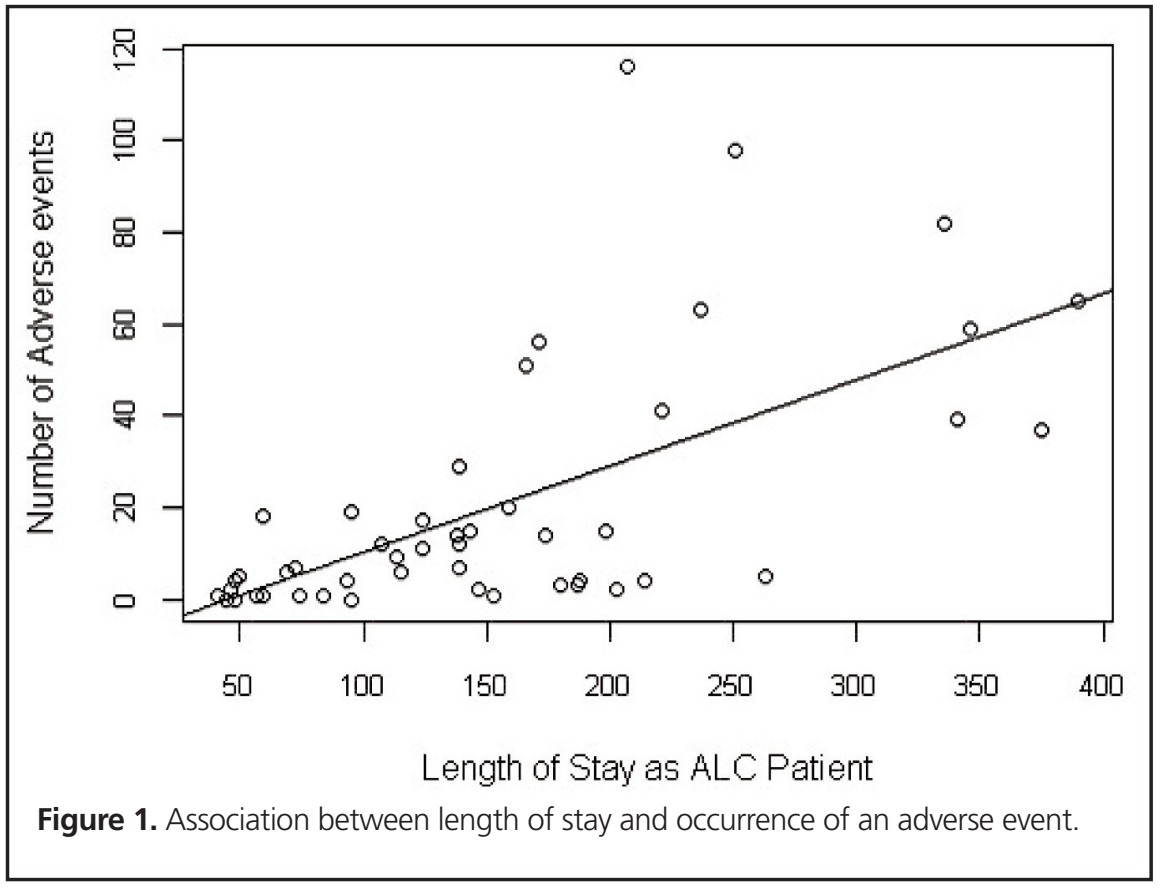

who were having more dementia-related CNS events were taking medications such as antipsychotics and benzodiazepines to control their behavioural and psychological symptoms of dementia. In other words, behavioural signs and symptoms that were recorded as adverse events in this study may actually have been part of the patient's dementia syndrome. At the same time, there is evidence that medications such as antipsychotics and benzodiazepines contribute to the behavioural and psychological symptoms of dementia. ${ }^{6}$ Notably, Mini-Mental State Examination $^{20}$ scores were not always available, and the diagnosis of dementia was not always clearly documented. For this reason, it was not possible to control for the severity of dementia. Applying a neuropsychiatric scale ${ }^{20}$ designed to identify the extent and severity of behavioural and psychological symptoms of dementia would have provided more specific diagnostic information; however, doing so would have been challenging, given time and resource constraints for this 12-month pharmacy residency project.

The data showed that dimenhydrinate PRN was ordered for $42 \%$ of the patients during their ALC stay. Dimenhydrinate has strong anticholinergic properties. ${ }^{6}$ Even the incident use of drugs with strong anticholinergic properties can contribute to impaired cognition and memory, as well as the onset of delirium. ${ }^{21,22}$

Antipsychotics were used for $40 \%$ of the population. Antipsychotic treatment of behavioural disturbances in dementia has limited efficacy and is recommended only after environmental and nonpharmacologic techniques have been implemented. ${ }^{23,24}$ Antipsychotics have been associated with an increased risk of death due to cardiovascular or infectious causes and an increased risk of adverse events such as morbidity due to falls and venous thromboembolism. ${ }^{24}$ Psychoactive medications (for long-term or
PRN use) that are ordered for appropriate reasons (e.g., diagnosis of schizophrenia or psychotic symptoms or when behavioural and psychological symptoms of dementia become dangerous to the patient or others ${ }^{6,23,24}$ ) should be routinely reassessed and, if appropriate, attempts at drug withdrawal should be made approximately every 3-6 months. ${ }^{24,25}$

This study identified a positive association between length of stay in an elderly ALC population and number of adverse events associated with a PIM, specifically adverse CNS events and falls. A recent study in a large Canadian health region found that morbid obesity, psychiatric diagnosis, abusive behaviours, and stroke were the factors significantly associated with greater ALC lengths of stay ${ }^{3}$; however, there was no attempt to link length of stay with adverse events or PIM use. A recent Italian study found that a longer hospital stay was a predictor for at least one PIM during the hospitalization, but associated adverse events were not evaluated. ${ }^{26} \mathrm{~A}$ study of critically ill elderly patients found that PIM use and a higher drug burden index were associated with poor clinical outcomes and longer lengths of stay. ${ }^{27}$ Finally, a prospective cohort study designed to identify risk factors for adverse outcomes during hospitalization found no association between PIM use and either adverse drug events or length of stay more than 7 days. ${ }^{28}$

In general, patients who have ALC status for longer periods are more likely to have difficulties being placed in a long-term care facility. ${ }^{2}$ The average length of ALC stay in this study was 156 days (SD 94.2). This wait time is worth noting because deconditioning is frequently associated with hospitalization of elderly people and has been linked to falls, functional decline, increased frailty, and immobility. ${ }^{29}$ Walking programs have been shown to prevent or postpone a further decline in executive 
function among those who are sedentary. ${ }^{30}$ However, such programs may not always be in place for ALC patients, as was the case in the study institution. The absence of a walking program further strengthens the argument that ALC patients may be at a higher risk of adverse events, especially those who have ALC status for longer and those who are exposed to PIMs.

Given the findings of this study, the study institution's approach to medication reviews for ALC patients is being reevaluated. Implementation of more frequent pharmacist medication reviews or follow-up may be warranted. This potential modification in approach would align well with objective 1.2 of the CSHP 2015 initiative, which states that "the medication therapy of $100 \%$ of hospital inpatients with complex and highrisk medication regimens will be monitored by a pharmacist." 31

This study had the advantage of incorporating a wellrounded Project Advisory Team. The clinical experience and expertise of team members allowed the use of a research-friendly explicit criteria tool, while taking into account individual patient circumstances for more complex cases.

The study had several limitations. Because of time and resource limitations, medication administration records were not reviewed to determine whether PRN medications had been administered before each adverse event. As a result, PRN medications could not be associated with adverse events. Despite the use of predetermined keywords, adverse events might have been missed or misclassified because of illegible handwriting or improper documentation. It was beyond the scope and resources of this study to investigate all possible adverse events listed in the Beers criteria or to conduct extensive chart reviews to count the total number of medications at each time point. ${ }^{6}$ The adverse events chosen were those that the research team believed to be most consistently and reliably documented and those with the most significant impact. Finally, with no control group, this study was not designed to establish causation.

\section{CONCLUSIONS}

Most patients in the ALC population at the study site were taking medications that were potentially inappropriate, according to the updated Beers criteria. Of the targeted adverse events, $44.1 \%$ may have been associated with a PIM.

This exploratory study has identified various avenues for future research. A prospective study of adverse events in relation to both regularly administered and PRN medications would provide more information about the impact of PRN PIMs. A trial comparing PIM use among hospitalized ALC patients and residents of long-term care facilities would provide valuable information on the differences between ALC patients and patients who actually reach long-term care homes. Such a study would have the potential to influence practice change and policy.

In accordance with objective 1.2 of the CSHP 2015 initiative, the results of this project lend support to the implementation of scheduled medication reviews by pharmacists for the ALC population, both to mitigate medication-related adverse events and to potentially reduce the time that patients wait for admission to a nursing home.

\section{References}

1. Analysis in brief: alternate level of care in Canada. Ottawa (ON): Canadian Institute for Health Information; 2009 Jan [cited 2012 Aug 8]. Available from: https://secure.cihi.ca/free_products/ALC_AIB_FINAL.pdf

2. The long stay alternate level of care (ALC) review 2012. Final report. Toronto (ON): Toronto Central LHIN; 2012 Aug.

3. Costa AP, Poss JW, Peirce T, Hirdes JP. Acute care inpatients with long-term delayed-discharge: evidence from a Canadian health region. BMC Health Serv Res. 2012;12:172.

4. Jarrett P, McCloskey R, McCollum A, Oakley H, Stewart C. What do we know about the patients who are alternate level of care in Horizon Health Network [abstract]. Can Geriatr J. 2013;162(2):86.

5. Health and Aging Network standards. Miramichi (NB): Horizon Health Network; [updated 2012 Sep 21].

6. American Geriatrics Society 2012 Beers Criteria Update Expert Panel. American Geriatrics Society updated Beers criteria for potentially inappropriate medication use in older adults. J Am Geriatr Soc 2012;60(4):616-31.

7. Jano E, Aparasu RR. Healthcare outcomes associated with Beers' criteria: a systematic review. Ann Pharmacother. 2007;41(3):438-47.

8. Lund BC, Carnahan RM, Egge JA, Chrischilles EA, Kaboli PJ. Inappropriate prescribing predicts adverse events in older adults. Ann Pharmacother. 2010;44(6):957-63.

9. Onder G, Landi F, Cesari M,, Gambassi G, Carbonin P, Bernabei R; Investigators of the GIFA Study. Inappropriate medication use among hospitalized older adults in Italy: results from the Italian Group of Pharmacoepidemiology in the Elderly. Eur J Clin Pharmacol. 2003;59(2):157-62.

10. Stockl KM, Le L, Zhang S, Harada AS. Clinical and economic outcomes associated with potentially inappropriate prescribing in the elderly. Am J ManagCare. 2010;16(1):e1-10.

11. Weston AL, Weinstein AM, Barton C, Yaffe K. Potentially inappropriate medication use in adults with mild cognitive impairment. J Gerontol A Biol Sci Med Sci. 2010;65(3):318-21.

12. Resnick B, Pacala JT. 2012 Beers criteria [editorial]. J Am Geriatr Soc. 2012;60(4):612-3.

13. Protecting the personal and financial interests of vulnerable persons. Fredericton (NB): Government of New Brunswick, Office of the Public Trustee; 2008 [cited 2009 Sep 9]. Available from: www.gnb.ca/0062/ pt-cp/pdf/publictrusteebrochure-e.pdf

14. Dimitrow MS, Airaksinen MS, Kivelä SL, Lyles A, Leikola SN. Comparison of prescribing criteria to evaluate the appropriateness of drug treatment in individuals aged 65 and older: a systematic review. J Am Geriatr Soc. 2011;59(8):1521-30.

15. Vieira de Lima TJV, Garbin CAS, Garbin AJI, Sumida DH, Saliba O. Potentially inappropriate medications used by the elderly: prevalence and risk factors in Brazilian care homes. BMC Geriatr. 2013;13:52.

16. Blozik E, Rapold R, von Overbeck J, Reich O. Polypharmacy and potentially inappropriate medication in the adult, community-dwelling population in Switzerland. Drugs Aging. 2013;30(7):561-8.

17. Cannon KT, Choi MM, Zuniga MA. Potentially inappropriate medication use in elderly patients receiving home health care: a retrospective data analysis. Am J Geriatr Pharmacother. 2006;4(2):134-43.

18. Buck MD, Atreja A, Brunker CP, Jain A, Suh TT, Palmer RM, et al. Potentially inappropriate medication prescribing in outpatient practices: prevalence and patient characteristics based on electronic health records. Am J Geriatr Pharmacother. 2009;7(2):84-92.

19. Opondo D, Eslami S, Visscher S, de Rooij SE, Verheij R, Korevaar JC, et al. Inappropriateness of medication prescriptions to elderly patients in the primary care setting: a systematic review. PLoS One. 2012;7(8):e43617.

20. Behavioral and psychological symptoms of dementia (BPSD) educational pack. Northfield (IL): International Psychogeriatric Association; 2003 [cited 2012 Sep 9]. Available from: www.ipa-online.org/pdfs/BPSD

21. Shah RC, Janos AL, Kline JE, Yu L, Leurgans SE, Wilson RS, et al. Cognitive decline in older persons initiating anticholinergic medications. PLoS One. 2013;8(5):e64111. 
22. Campbell N, Boustani M, Limbil T, Ott C, Fox C, Maidment I, et al. The cognitive impact of anticholinergics: a clinical review. Clin Interv Aging. 2009;4:225-33.

23. Reuben DB, Herr KA, Pacala JT, Pollock BG, Potter JF, Semla TP. Dementia. In: Geriatrics at your fingertips. 15th ed. New York (NY): American Geriatrics Society; 2013. p. 62-8.

24. A guide to the management of psychotic disorders and neuropsychiatric symptoms of dementia in older adults. New York (NY): American Geriatrics Society; 2011 [cited 2012 Sep 9]. Available from: https://www. nhqualitycampaign.org/files/AGS_Guidelines_for_Telligen.pdf

25. Best practice guideline for accommodating and managing behavioral and psychological symptoms of dementia in residential care: a person-centered interdisciplinary approach. Victoria (BC): Government of British Columbia; 2012 Oct 25 [cited 2013 May]. Available from: www.health.gov.bc.ca/ library/publications/year/2012/bpsd-guideline.pdf

26. Napolitano F, Izzo MT, Di Giuseppe G, Angelillo IF; Collaborative Working Group. Frequency of inappropriate medication prescription in hospitalized elderly patients in Italy. PLoS One. 2013;8(12):e82359.

27. Floroff CK, Slattum PW, Harpe SE, Taylor P, Brophy GM. Potentially inappropriate medication use is associated with clinical outcomes in critically ill elderly patients with neurological injury. Neurocrit Care. 2014; 21(3):526-33

28. Borenstein J, Aronow HU, Bolton LB, Choi J, Bresee C, Braunstein GD. Early recognition of risk factors for adverse outcomes during hospitalization among Medicare patients: a prospective cohort study. BMC Geriatr. 2013; 13:72.

29. Gillis A, MacDonald B. Deconditioning in the hospitalized elderly. Can Nurse. 2005;101(6):16-20.

30. Scherder E, Scherder R, Verbugh L, Königs M, Blom M, Kramer AF, et al. Executive functions of sedentary elderly may benefit from walking: a systematic review and meta-analysis. Am J Geriatr Psychiatry. 2014;22(8): 782-91.

31. Canadian hospital pharmacy 2015 (CSHP 2015). CSHP goals and objectives for pharmacy practice in hospitals and related healthcare settings to be achieved by 2015. Ottawa (ON): Canadian Society of Hospital Pharmacists; 2014 [cited 2014 Sep 8]. Available from: http://cshp.ca/ dms/dmsView/2_CSHP-2015-Goals-and-Objectives-Feb-25\%2707-wAppdx-rev-May\%2708.pdf
Heather Slaney, BSCPharm, ACPR, was, at the time this study was conducted, a Pharmacy Resident at The Moncton Hospital, Moncton, New Brunswick. She is now a Clinical Pharmacist at the Janeway Children's Health and Rehabilitation Centre, Eastern Health, St John's, Newfoundland and Labrador.

Stacey MacAulay, BScPharm, PharmD, is Residency Coordinator and Pharmacy Clinical Practice Leader (Ambulatory Care), Horizon Health Network, The Moncton Hospital, Moncton, New Brunswick, and Adjunct Professor, College of Pharmacy, Dalhousie University, Halifax, Nova Scotia.

Janice Irvine-Meek, BSC(Pharm), PharmD, FCSHP, RPh, was, at the time this study was conducted, Clinical Manager and Clinical Pharmacy Specialist, Geriatrics, The Moncton Hospital, Moncton, New Brunswick.

Joshua Murray, MSc, is a Biostatistician with the Health Research Unit, Horizon NB, Horizon Health Network, The Moncton Hospital, Moncton, New Brunswick.

\section{Address correspondence to:}

Heather Slaney

Pharmacy Department

Janeway Children's Health and Rehabilitation Centre

300 Prince Philip Drive

St John's NL A1B 3V6

e-mail: heather.slaney@easternhealth.ca

Acknowledgements: The authors thank Dr. Marie-Eve Blanchard (Geriatrician), Lise Savoie (Registered Nurse) and Margaret Willan (Pharmacist) for their support and contributions as members of the Project Advisory Team.

Funding: Sandoz provided a travel grant to pharmacy residents at the Moncton Hospital but was not involved in the design or conduct of the study; the collection, management, or interpretation of the data; or the preparation, review, or approval of the manuscript.

\section{Appendix 1. Non-Canadian Beers Criteria medications removed from data collection tool}

\section{amobarbital}

amoxapine

butabarbita

carbinoxamine

carisoprodol

cilostazol

desiccated thryoid

dexchlorpheniramine

dofetilide estazolam

eszopiclone

fenoprofen

guanabenz

guanfacine

iloperidone

isoxsuprine

meclizine

meclofenamate mephobarbital

mesoridazine

metaxalone

methyltestosterone

molindone

pemoline

propantheline

protriptyline

quazepam reserpine

secobarbital

thioridazine

tolmetin

triflupromazine

trimethobenzamine

zaleplon 